\title{
ANALISIS PENGARUH FLEXIBLE HRM TERHADAP FIRM INNOVATIVENESS YANG DIMEDIASI INNOVATIVE WORK BEHAVIOR (STUDI KASUS PADA PT XYZ)
}

\author{
Kevin Matthew Aditya \\ Program Studi Magister Manajemen Universitas Tarumanagara \\ Kevinmatthew93@gmail.com
}

\begin{abstract}
Innovation is one of the strategic prerequisites for companies if they want to have an advantage in competition. But to realize this is not easy, because it must also be supported by the flexibility of human resource management and employee behavior that must also be innovative. Based on this background, the purpose of this study was to analyze the direct influence of Flexible HRM, and Innovative Work Behavior on Firm Innovativeness; and the indirect effect of Flexible HRM on Firm Innovativeness through Innovative Work Behavior. This research approach is quantitative, with a type of causal research. The population is all PT XYZ permanent employees in Jakarta, totaling more than 700 employees, and a sample of 100 employees. The sampling technique is incidental sampling. Techniques for collecting data through face-to-face surveys, using questionnaires on a 1-5 Likert scale. Data analysis methods are descriptive analysis, multiple linear regression, and path analysis. The results showed that Flexible HRM and Innovative Work Behavior had a positive and significant effect on Firm Innovativeness. In addition, Innovative Work Behavior proved to play a role in mediating the influence of Flexible HRM on Firm Innovativeness.
\end{abstract}

Abstrak: Inovasi menjadi salah satu prasyarat strategis bagi perusahaan jika hendak memiliki keunggulan dalam bersaing. Namun untuk mewujudkan hal itu tidak mudah, karena juga harus didukung oleh fleksibilitas menajemen sumber daya manusia maupun perilaku pegawai yang juga harus inovatif. Berdasarkan latar belakang itu, tujuan penelitian ini adalah untuk menganalisis pengaruh langsung Flexible HRM, dan Innovative Work Behavior terhadap Firm Innovativeness; serta pengaruh tidak langsung Flexible HRM terhadap Firm Innovativeness melalui Innovative Work Behavior. Pendekatan penelitian ini kuantitatif, dengan tipe penelitian kausal. Populasi adalah semua pagawai tetap PT XYZ di Jakarta yang berjumlah lebih 700 pegawai, dan sampel 100 pegawai. Teknik pengambilan sampel adalah incidental sampling. Teknik pengambilan data melalui survei tatap muka, menggunakan kuesioner dengan skala Likert 1-5. Metode analisis data adalah analisis deskriptif, regresi linear berganda, dan analisis jalur (path analysis). Hasil penelitian menunjukkan, Flexible HRM, dan Innovative Work Behavior berpengaruh positif dan signifikan terhadap Firm Innovativeness. Selain itu, Innovative Work Behavior terbukti berperan memediasi pengaruh Flexible HRM terhadap Firm Innovativeness.

Keywords : Flexible HRM, Innovative Work Behavior, and Firm Innovativeness.

\section{PENDAHULUAN}

Era digital telah mengubah fenomena ekonomi lama (old economy) menjadi ekonomi baru (new economy), dan hal ini telah menuntut perubahan besar dalam strategi perusahaan. Perusahaan dewasa ini menghadapi persaingan ketat dalam lingkungan pasar yang dinamis, tidak pasti dan yang mengalami transformasi sangat kompleks. Untuk mencapai keunggulan bersaing, atau bahkan sekedar untuk tetap bertahan hidup, perusahaan ditantang untuk semampu mungkin beradaptasi dan merespon lingkungan baru dengan fleksibel, serta 
menyampaikan gagasan dan produk baru (Jiang et al., 2012). Manajemen sumber daya yang fleksibel (Flexible HRM) merupakan elemen penting dalam HRM strategis sebagai kemampuan internal perushaan dan merupakan prasyarat untuk keunggulan kompetitif yang berkelanjutan (Kozica \& Kaiser, 2012). Flexible HRM dapat mengkaji sejauh mana peerushaan dapat dengan cepat dan efektif membuat penyesuaian seiring dengan perbahan lingkungan perusahaan (Chen \& Li, 2015).

Perusahaan yang menerapkan strategi kreatif dan inovatif harus membina karyawan agar memiliki perilaku kewirausahaan dan perilaku inovatif. Penting untuk mengetahui penyebab individu karyawan di tempat kerja berperilaku inovatif, dan bagaimana perusahaan membentuk perilaku inovatif (Eenink, 2012). Perilaku kerja yang inovatif (innovative work behavior) diyakini merupakan faktor penting ketika berurusan dengan perubahan inkremental dan transformasional dan dalam mencapai keunggulan kompetitif organisasi (Jansen, 2000). Innovative Work Behavior merupakan perilaku individudalam mengeksplorasi, membangkitkan, memperjuangkan dan menghasilkan gagasan, produk, proses atau prosedur yang baru dan efektif (Feldman \& Lam, 2010).

Dalam menghadapi persaingan bisnis pada lingkungan baru yang cepat berubah, manajemen sumber daya manusia dituntut untuk bisa fleksibel. Fleksibilitas ini memungkinkan perushaan mampu beradaptasi dengan lingkungan internal maupun eksternal yang dinamis. Manajemen sumber daya manusia yang fleksibel merupakan aspek penting dalam fleksibiltas perushaan untuk membentuk atribut pegawai (Javed et al., 2017).

HRM yang inovatif diharapkan dapat menciptakan perushaan yang inovatif (firm innovativeness). Firm innovativeness merupakan faktor penting untuk berkompetisi dalam lingkungan yang berubah bahkan juga penting untuk sekedar mempertahankan kelangsungan hidup perusahaan. Inovasi perusahaan meliputi inovasi produk, inovasi proses, dan inovasi administrasi (Javed et al., 2017).

Berdasarkan latar belakang tersebut, penulis tertarik untuk melakukan penelitian di Jakarta yang melibatkan tiga variabel kepegawaian strategis tersebut dengan merujuk pada penelitian Javed et al. (2017) berjudul "Flexible human resourcs management and firm innovativeness: the mediating role of innovative work behavior" yang melakukan penelitian di Lahore, Pakistan.

\section{RUMUSAN MASALAH DAN TUJUAN PENELITIAN}

\section{Rumusan masalah penelitian ini adalah :}

1. Bagaimana pengaruh flexible HRM terhadap innovative work behaviors pegawai

2. Bagaimana pengaruh innovative work behaviour terhadap firm innovativeness

3. Bagaimana pengaruh flexible HRM terhadap firm innovativeness

4. Bagaimaa pengaruh innovative work behavior memediasi pengaruh flexible HRM terhadap firm innovativeness

\section{Tujuan penelitian ini adalah :}

1. Menganalisis pengaruh flexible HRM terhadap innovative work behavior

2. Menganalisis pengaruh innovative work behavior terhadap firm innovativeness

3. Menganalisis pengaruh flexible HRM terhadap firm innovativeness

4. Menganalisis peran innovative work behavior dalam memediasi pengaruh flexible HRM terhadap firm innovativeness 


\section{TINJAUAN PUSTAKA}

\section{Flexible HRM}

Manajemen sumber daya manusia strategis atau strategic human resource management (SHRM) didefinsikan Wright dan McMahan (1992) merupakan pola pengerahan dan kegiatan sumber daya manusia yang direncanakan, yang dimaksudkan untuk memungkinkan organisasi mencapai tujuannya.

Studi SHRM telah berfokus pada eksplorasi peran strategis yang dapat dimainkan SDM dalam meningkatkan efektivitas organisasi. SDM menjadi salah satu faktor startegis, bukan hanya menyangkut peran yang dimainkan SDM yang menjadikan strategi manajerial menjadi berdampak, namun juga berpotensi menjadi sumber keunggulan bersaing secara berkelanjutan (sustainable competitive advantage) (Wang \& Shyu, 2008).

Pengembangan lain dari SHRM adalah manajemen sumber daya manusia yang fleksibel (flexible human resource management). SHRM yang fleksibel memungkinkan perusahaan untuk mengencangkan maupun mengadaptasi pada perubahan maupun persyaratan/tuntutan yang tidak menentu dan beragam, baik yang berasal dari lingkungan internal maupun lingkungan eksternal (Javed et al., 2017).

Fleksibilitas manajemen SDM berdampak pada perilaku kerja yang inovatif, karena manajemen SDM menargetkan keterampilan, motivasi, kemampuan, hingga bagaimana meningkatkan peluang (Pulkene, 2016).

Wright dan Snell (1998) mengidentifikasi bahwa Flexible HRM memiliki tiga dimensi, meliputi fleksibilitas perilaku pegawai (employee behavior flexibility), fleksibilitas keterampilan pegawai (employee skills flexibility), dan fleksibilitas praktek HR (HR practice flexibility).

\section{Firm Innovativeness}

Inovasi perusahaan (firm innovativeness) pada dasarnya merupakan faktor penting untuk bersaing dalam lingkungan bisnis yang berubah, dan bahkan penting untuk kelangsungan hidup perusahaan. Inovasi perusahaan didefinisikan sebagai "the adoption on an idea or behavior, whether a system, policy, program, device, process, product or services, that is new to adopting organization" (Damanpour et al., 1989). Berarti inovasi perusahaan merupakan adopsi dari sebuah gagasan atau perilaku, apakah suatu sistem, kebijakan, program, perangkat, proses, produk atau layanan, yang baru untuk diadopsi organisasi.

Utterback \& Abernathy dalam Jaidev (2017) mengemukakan tiga dimensi inovasi perusahaan. Ketiga inovasi tersebut adalah (i) Inovasi produk (product innovations), yakni kreasi dan komeresialisasi produk baru untuk memenuhi kebutuhan dan keinginan konsumen. (ii) Inovasi proses (process innovation), yakni kreasi menyangkut proses atau modifikasi pada proses, metode atau teknik yang telah ada pada (existing) pada pereusahaan. (iii) Inovasi administrasi (administrative innovation), yakni menempatkan rutinitas dan prosedur yang efektif dalam unit administrasi, perusahaan, pengiriman, layanan, dan dukungan .

\section{Innovative Work Behavior}

Perilaku kerja yang inovatif (innovative work behavior) diyakini menjadi faktor dalam menangani perubahan inkremental dan transformasional, dan untuk mencapai keunggulan kompetitif (Jansen, 2000). Perilaku kerja yang inovatif dapat digambarkan sebagai rasa perilaku individu dalam mengeksplorasi, menghasilkan, memperjuangkan, dan mengimplementasikan ide, produk, proses, atau prosedur yang baru dan efektif (De Jong \& DenHartog, 2010). 
Jannsen (2000) meyebutkan bawa perilaku inovatif merupakan tiga proses yang terdiri atas membangkitkan ide (idea generation), mempromosikan ide (idea promotion), dan melaksanakan ide (idea promotion). Perilaku inovatif dimulai dari tahap pembangkitan gagasan yang merupakan penciptaan ide baru dan ide ini berguna meskipun berada di bawah domain apa pun.

Mumford (2000) menyatakan bahwa pegawai merupakan satu-satunya sumber gagasan baru di tempat kerja. Pembangkit gagasan yang efektif adalah pegawai yang dapat mendekati kinerja atau masalah kesenjangan melalui dimensi yang unik. Pada dasarnya pembangkiu ide yang efektif adalah mereka yang membawa gagasan, proses yang baru dan unik dalam upaya untuk memecahkan masalah tertentu atau mungkin dalam rangka upaya untuk membawa perbaikan (Pukiene, 2016).

Tahap berikut dari perilaku inovatif adalah mempromosikan gagasan (idea promotion). Pada tahap ini pegawai yang menghasilkan gagasan baru mencari dukungan, misalnya dengan jalan mendiskusikannya dengan kolgea, atasan, atau mungkin teman sendiri, atau bahkan sponsor (Kanter, 1988; Puikene, 2016)

Realisasi ide (idea realization) merupakan tahap terakhir perilaku inovatif. Realisasi ide berarti mengubah gagasan baru menjadi output yang efektif (Pukiene, 2016). Pada tahap ini, gagasan yang telah dibangkitkan dan dipromosikan tersebut kemudian diimplemantasikan dan digabungkan/diintegrasikan ke dalam agenda aksi (de Jong, 2008). Gagasan pada tahap ini menjadi prototipe, realitas atau model yang dapat disentuh, dialami dan dibawa ke dalam implementasi (Kanter, 1998).

\section{HIPOTESIS PENELITIAN}

Berdasarkan rumusan, tujuan penelitian, dan tinjauan pustaka maka disusun hipotesis penelitian sebagai berikut:

Hipotesis 1 : Flexible HRM berpengaruh positif terhadap innovative work behavior.

Hipotesis 2 : Innovative work behavior berpengaruh positif terhadap firm innovativeness.

Hipotesis 3 : Flexible HRM berpengaruh positif terhadap firm innovativeness.

Hipotesis 4 : Innovative work behavior memediasi secara positif pengaruh flexible HRM terhadap firm innovativeness.

\section{METODE PENELITIAN}

Penelitian ini menggunakan pendekatan kuantitatif dengan metode survei. Populasi dalam penelitian ini adalah segenap karyawan PT XYZ yang berdomisili di Jakarta. Penentuan jumlah sampel dalam penelitian ini menggunakan rumus Tabachnick \& Fidell (2013). Jumlah sampel yang ditetapkan pada penelitian ini adalah 100 responden.

Periode penelitian yang digunakan dalam rentang waktu tiga bulan, mulai September 2018 sampai dengan Desember 2018. Teknik pengambilan sampel adalah sampel insidental (incidental sampling), yakni siapa saja yang secara kebetulan lebih dahulu dapat ditemui surveyor dan sesuai kriteria populasi, serta yang bersangkutan bersedia menjadi responden, sampai jumlahnya memenuhi jumlah sampel yang ditetapkan (Sugiyono, 2013: 126).

\section{HASIL DAN PEMBAHASAN}

\section{Hasil Uji Validitas}

Dengan asumsi jumlah responden pengujian adalah $30(\mathrm{n}=30)$ dan derajat kebebasan adalah 0,05 ; maka nilai "r tabel" adalah 0,361 
Dari hasil pengujian menggunakan bantuan program SPSS didapat semua pernyataan pada ketiga variabel (Flexible HRM, Innovative Work Behavior, dan Firm Innovativeness) valid, karena nilai $\mathrm{r}$ hitung $>\mathrm{r}$ tabel.

\section{Hasil Uji Reliabilitas}

Variabel yang reliabel adalah variabel memenuhi persyaratan minimal reliabilitas yaitu koefisien Cronbach's Alpha > 0,60 (Sugiyono, 2013).

Dari hasil pengujian reliabilitas metode per variable didapatkan semua variabel reliable, karena nilai Cronbach's Alpha >0,60.

\section{Hasil Uji Normalitas}

Data hasil penelitian ketiga variabel didapat ketiganya terdistribusi normal karena Asymp Sig. Lebih besar daripada 0,05 (Enterprise, 2014: 47).

\section{Pembahasan Model 1: Pengaruh Flexible HRM $\left(\mathrm{X}_{1}\right)$ terhadap Firm Innovativeness (Y)}

Hasil penelitian membuktikan Flexible $H R M\left(\mathrm{X}_{1}\right)$ secara langsung bepengaruh positif dan signifikan terhadap Firm Innovativeness (Y). Hasil penelitian ini membuktikan bahwa HRM pada PT XYZ cukup fleksibel untuk menyesuaikan dengan perilaku kerja inovatif perusahaan yang umumnya sangat dinamis, karena mengikuti perkembangan internal perusahaan maupun lingkungan bnisnis yang juga dinamis.

\section{Pembahasan Model 2: Pengaruh Flexible HRM $\left(\mathrm{X}_{1}\right)$ terhadap Innovative Work Behavior $\left(\mathbf{X}_{2}\right)$}

Hasil penelitian membuktikan Flexible HRM $\left(\mathrm{X}_{1}\right)$ secara langsung bepengaruh positif dan signifikan terhadap Innovative Work Behavior $\left(\mathrm{X}_{2}\right)$. Hasil penelitian ini membuktikan bahwa HRD pada PT XYZ cukup felskibel untuk menyesuaikan dengan perilaku kerja inovatif yang umumnya sangat dinamis. Berarti koordinasi HRM dengan berbagai strategi dan program bagian lain dari perusahaan cukup intens, karena perilaku inovasi ini bukan hanya sangat dinamis, namun juga variatif.

\section{Pembahasan Model 3: Pengaruh Innovative Work Behavior $\left(\mathrm{X}_{2}\right)$ terhadap Firm Innovativeness (Y)}

Hasil penelitian membuktikan Flexible HRM ( $\left.\mathrm{X}_{1}\right)$ secara langsung berpengaruh positif dan signifikan terhadap Firm Innovativeness (Y). Berarti selama ini, aspek inovasi pada PT XYZ telah termasuk bagian dari strategi HRM juga. Oleh karena itu tidak heran jika hasil penelitian ini membuktikan bahwa perilaku kerja inovatif mempengaruhi inovasi HRM

\section{Pembahasan Model 4: Pengaruh Innovative Work Behavior $\left(\mathrm{X}_{2}\right)$ dalam memediasi Pengaruh Flexible HRM ( $\left.\mathrm{X}_{1}\right)$ terhadap Firm Innovativeness (Y)}

Hasil penelitian membuktikan Innovative Work Behavior (X2) berperan memediasi pengaruh Flexible HRM $\left(\mathrm{X}_{1}\right)$ terhadap Firm Innovativeness $(\mathrm{Y})$. Berarti pada PT $\mathrm{X}$ telah terjadi hubungan yang harmonis, saling mempengaruhi, dan terkoordinasi antara satu bagian dengan bagian lain secara horiziontal maupun vertikal.

\section{KESIMPULAN}

Berdasarkan hasil penelitian dan dihubungkan dengan tujuan penelitian maupun hipotesis penelitian, maka dapat disimpulkan:

- Flexible HRM berpengaruh positif dan signifikan terhadap Firm Innovativenss. 
- Flexible HRM berpengaruh positif dan signifikan terhadap Innovative Work Behavior.

- Innovative Work Behavior. berpengaruh positif dan signifikan terhadap Firm Innovativenss.

- Innovative Work Behavior berperan memediasi pengaruh Flexible HRM terhadap Firm Innovativenss.

\section{SARAN}

- Hendaknya jumlah variabel ditambah dari jumlah variabel penelitian ini, sehingga lebih banyak hal yang bisa terungkap dalam penelitian selanjutnya.

- Hendaknya jumlah penelitian terdahulu dicari kembali agar jumlahnya lebih banyak

- Boleh dicoba pendekatan untuk penelitian selanjutnya adalah pendekatan kombinasi (mixed-method) agar hasil penelitian lebih komprehensif.

- Lokasi penelitian bisa ditambah minimal satu perusahaan, sehingga bisa dilakukan perbandingan. Bisa juga tetap dalam satu perusahaan, namun dibuat perbandingan antar-divisi/departemen.

\section{DAFTAR PUSTAKA}

Alkhazali, Z., \& Halim, M.A. (2015). The influence of strategic human resource management on firm perfirmance of Joprdan's corporate organization. Internatioal Journal of Academic Research in Business and Social Sciences, 5(12): 342- 353.

Al-Ragggad, M.A. (2014). Strategic human resource management and firm performance in Jordan Listed Firms. European Scientific Journal, 10(13): 402- 421.

Bondarouk, T., Trullen, J., \& Valverde, M. (2016). Special issue of international Journal of Human Resource Management: Conceptual and empirical discoveries in successful HRM implementation. The International Journal of Human Resource Management, DOI: 10.1080/09585192.2016.1154378, 1-4.

Brito, R.P.d., \& Oliveira, L.B.d. (2016). The relationship between human resource management and organizational performance. Brazilian Business Review, 13(3): 90110.

Byermo, C. (2015). Human resource management and organisational performance: Does HRM lead to improved organisational performance? Master's thesis in organisation, leadership and work, Department of Sociology and Human Geography, Faculty of Social Sciences, University of Oslo. Diunduh tanggal 15 Juli 2018 jam 19.42 WIB dari https://www.duo.uio.no/bitstream/handle/10852/49030/Cathrine-Byremo-2015--HRM-and-Organisational-Performance--Does-HRM-lead-to-improved-organisationalperformance-.pdf?sequence $=1$ \&is Allowed $=\mathrm{y}$

Cooper, D.R. \& Schindler, P.S. (2014). Business Research Methods. International Edition. AT Boston: McGraw-Hill.

Ekwoaba, J.O., Ikeije, U.U., \& Ufoma, N. (2015). The impact of recruitment and selection criteria on organizational performance. Global Journal of Human Resource Management, 3 (2): 22-33.

Ghozali, I. (2012). Aplikasi Analisis Multivariate dengan Program IBM SPSS 20. Semarang: Badan Penerbit Universitas Diponegoro.

Javed, A., Anas, M., Abbas, M., \& Khan, A.I. (2017). Flexible human resources management and firm innovativeness: the mediating role of innovative work behavior. Journal of Human Resource Management, XX (1): 31- 41. 
Jeong, D.Y., \& Choi, M. (2016). The impact of high-performance work systems on firm performance: the moderating effects of the human resource function's influence. Journal of Management of Organization, 22(3): 328-348.

Kariithi, J. (2016). Impact of strategic human resource management practices on organizational performance ( a case study of safaricom). Human Rsource and Leadership Journal, 1(1): 1-18.

Kuncoro, Mudrajad. (2011).Metode Kuantitatif: Bisnis Teori dan Aplikasi untuk \& Ekonomi. Edisi Keempat. Yogyakarta: UPP STIM YKPN.

Mansour, M. (2015). The practice of strategic human resource management in a developing country. European Online Journal of Natural and Social Social Sciences, 4(3), 500517.

Palagolla, N.(2016). Empirical gaps in the relationship between HRM and firm performance: Future research perspective. International Journal of Business and Management Review, 4(5), 96-103.

Rankin, S. (2015). Perspectives on human practices: divergence in time, theoritical linkages, and process. A thesis submitted to the faculty of graduate study in partial fulfilment of the requiarements for the degree of doctor of philosophy, Graduate Program in Mangement, Univesity of Calgary, Alberta. Diunduh tanggal 15 Juli 2018 jam 19.42 WIB dari https://prism.ucalgary.ca/bitstream/handle/11023/2545/ucalgary_2015_rankin_scott.p df;jsessionid=CB52AA597FC390E860D8BF28AB1592B6? sequence $=2$

Saridakis, G., Lai, Y., \& Cooper, C.L. (2016). Exploring the relationship HRM and firm performance: A meta-analysis of longitudinal studies. Human Resource Management Review, http://dx.doi.org/10.1016/j.hrmr2016.09.005: 2-10.

Sugiyono. (2013). Metode Penelitian Kombinasi(Mixed Methods). Bandung: Alfabeta.

Tabachnick, B.G., \& Fidell, L.S. (2013). Using Multivariate Statistics. Sixth Edition. Boston: Pearson.

Uysal, G. (2014). Taylor, HRM, strategic HRM with jobs, employee performance, business performance relationship: HR governance through 100 years. International Journal of Busines and Management Studies, 6(1): 87- 96.

Vermeeren, B., Steijn, B., Tummers, L., Lankhaar, M., Poerstamper, R.J., \& Beek, S.V. (2014). HRM and its effect on employee, organizational and financial outcomes in health care organizations. Human Resources for Health, 12(35): 1-9.

Widarjono, A. (2015). Analisis Multivariat Terapan dengan Program SPSS, AMOS dan SMARTPLS. Edisi kedua. Yogyakarta: UPP STIM YKPN

Yang, C.C., Lin, C.Y.Y. (2014). Does technical or strategic HRM provide a better explanation of organization performance. iBusiness, 6: 52-62.

Yilmaz, R., Bulut, F.M. (2015). The effect of human resources management on organisational performance. $K N U V, 2(44): 5-13$.

Zehir, G., Gurol, Y., Karaboga, T., \& Kole M. (2016). Strategic humn resource management and firm performance: the mediating role of entrepreneurial orientation. Prosiding: 12th International Strategic Management Conference, ISMC 2016, 28-20 October 2016, Antalya, Turkey. Procedia: Social and Behavioral Sciences, 235: 372-381. 
